\title{
Architecture, modernité, modernisation
}

\author{
Jean-Louis Cohen
}

\section{CpenEdition}

Journals

Édition électronique

URL : https://journals.openedition.org/lettre-cdf/1933

DOI : 10.4000/lettre-cdf.1933

ISSN : 2109-9219

Traduction(s) :

Architecture, Modernity and Modernization - URL : https://journals.openedition.org/lettre-cdf/2152 [en]

\section{Éditeur}

Collège de France

\section{Édition imprimée}

Date de publication : 1 mars 2015

Pagination : 6

ISSN : 1628-2329

\section{Référence électronique}

Jean-Louis Cohen, «Architecture, modernité, modernisation », La lettre du Collège de France [En ligne],

39 | mars 2015, mis en ligne le 01 août 2015, consulté le 17 août 2022. URL : http://

journals.openedition.org/lettre-cdf/1933; DOI : https://doi.org/10.4000/lettre-cdf.1933 


\section{Jean-Louis Cohen}

\section{Architecture, modernité, modernisation}

\section{Les rapports de l'architecture avec le champ de la connaissance, avec la littérature et avec la ville sont au centre du propos de cette conférence inaugurale. Dans le même temps qu'elle a dressé des palais - ou des usines - pour la recherche, au cours des deux derniers siècles, l'architecture empruntait à la science modèles et métaphores.}

Les sciences ont-elles été pour autant hospitalières à l'architecture comme discipline intellectuelle, comme champ de recherche en tant que tel ? Rien n'est moins sûr. Depuis 1970, elle a fait l'objet d'une véritable recherche scientifique, qui a contribué à une sorte de " reconstruction » intellectuelle de l'architecture en France. Les architectes sont loin d'avoir été les seuls protagonistes de cet effort collectif, et leurs travaux ont croisé ceux des historiens de l'art, des sociologues, des géographes et des urbanistes, tels qu'ils les ont entrepris dans leur champ disciplinaire ou institutionnel propre.

Questionner aujourd'hui la modernité en architecture ne revient pas seulement à recenser les éléments nouveaux apparus dans son lexique, ou, si l'on recourt à un modèle linguistique, à distinguer en suivant l'axe syntactique les nouveaux modes de composition et d'agrégation des formes imaginées depuis l'apparition du « mouvement moderne ». Dans le champ de l'architecture, le phénomène de la modernité se révèle en effet plus complexe qu'en art ou en littérature. Les formes et les espaces qui le manifestent s'ajustent aux programmes énoncés par ce dispositif plus englobant qui est celui de la modernisation, de la production, de la consommation, des territoires et plus amplement de la société, dispositif informé depuis le XIX ${ }^{\mathrm{e}}$ siècle par les hégémonies successives de l'Angleterre, de l'Allemagne ou de l'Amérique.

Beaucoup d'architectes ont entretenu par ailleurs un rapport intense avec la littérature, se révélant lecteurs autant que constructeurs. Ainsi le jeune Le Corbusier a-t-il dévoré, deux fois à cinquante ans de distance le Zarathoustra de Friedrich Nietzsche, au demeurant livre de chevet de beaucoup d'architectes de sa génération à travers l'Europe. Non contents d'être leurs lecteurs, les architectes sont aussi des interlocuteurs pour les écrivains et les philosophes, comme ils le sont parfois pour les artistes, et ils leur rendent hommage. Symétriquement, l'attention à l'archi- tecture a été partagée par nombre d'écrivains. L'architecture a aussi été considérée par ces derniers, dans ses principes et dans ses rapports avec les autres arts et la société, comme ce fut le cas pour Paul Valéry dès 1891, ou pour Georges Bataille, qui en dénonça l'oppression. Sa vibrante dénonciation s'appuyait sur une réduction implicite de l'architecture aux seuls grands édifices dans lesquels se condense le pouvoir. C'est pourtant au xx siècle que l'architecture a cessé de s'adresser exclusivement à l'aristocratie et à la bourgeoisie pour donner forme à des programmes destinés aux classes populaires.

La relation de l'objet architectural à l'espace urbain et au paysage a été au centre de l'attention depuis une cinquantaine d'années. L'enjeu ne se résume pas à l'ajustement matériel, à la ville, de l'immeuble, du monument ou de la maison, à l'emboitement d'un produit répondant à une commande privée ou à un programme public dans un ensemble plus complexe, déterminé par des considérations politiques et économiques. Les paramètres objectifs que sont la densité, la hauteur, l'axialité ou la topographie font l'objet d'interprétations artistiques subjectives dans lesquelles interviennent les mythes et les représentations, et qui laissent place à l'invention.

Pour rendre compte des cycles selon lesquels l'architecture s'est transformée, plutôt que de la considérer comme un domaine étanche, les conférences l'inscriront pleinement dans l'histoire, en pensant à la fois les continuités dans la durée, les crises et les ruptures. Multiples, les matériaux de cette histoire seront oraux, archivistiques, écrits, les premiers documents en étant les édifices, rapportés aux discours qui les ont générés et accompagnés. Pour les ordonner et les interpréter, un changement incessant de focale sera nécessaire. L'histoire de l'architecture appelle une navigation constante entre la vision des ensembles urbains, cadré en mode panoramique, qui rend compte des politiques sociales ou techniques et la vision en gros plan des édifices et de leurs intérieurs, qui rend compte des idéaux ou de l'engagement de leurs auteurs et de leurs habitants.

Extraits de la conférence inaugurale du 21 mai 2014

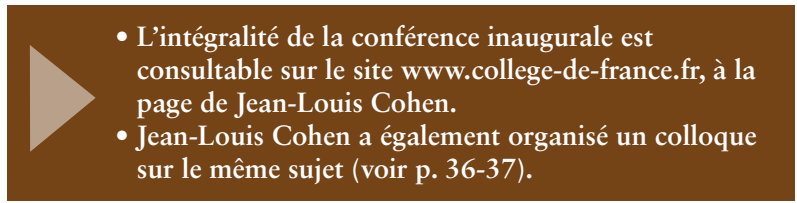

